\title{
Compositional features and bioactive properties of whole fraction from Aloe vera processing
}

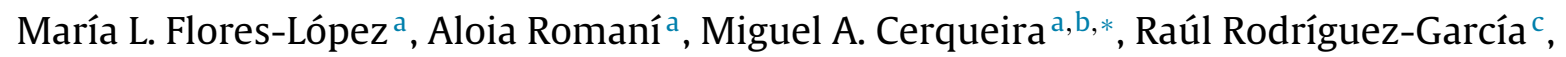 \\ Diana Jasso de Rodríguez ${ }^{\mathrm{c}, * *}$, António A. Vicente ${ }^{\mathrm{a}}$ \\ a Centre of Biological Engineering, Universidad do Minho, Campus de Gualtar, 4710-057 Braga, Portugal \\ b International Iberian Nanotechnology Laboratory, Av. Mestre José Veiga s/n, 4715-330 Braga, Portugal \\ c Universidad Autonoma Agraria Antonio Narro, Calzada Antonio Narro No. 1923, Colonia Buenavista, Saltillo, 25315 Coahuila, Mexico
}

\section{A R T I C L E I N F O}

\section{Article history:}

Received 4 March 2016

Received in revised form 7 July 2016

Accepted 11 July 2016

\section{Keywords:}

Organic acids

Phenolic compounds

Antioxidant activity

Antifungal activity

\begin{abstract}
A B S T R A C T
Aloe vera processing leaves generates a liquid and bagasse fraction. The resulting bagasse is mostly discarded as waste. Both the bagasse and liquid fraction can have interesting metabolites with biological activities for pharmaceutical and agro-food industries. The main objectives of the present work were: (1) to characterize the gel, liquid fraction and bagasse of $A$. vera; (2) to obtain extracts from bagasse (ethanolic extract, EE-B and aqueous extract, AE-B); and (3) to evaluate biological activity of gel, liquid and bagasse extracts in terms of the antifungal effect on phytopathogenic fungi and antioxidant activity by the DPPH radical scavenging method. The carbohydrates were the major component of $A$. vera fractions corresponding to $57.45,40.09$ and $58.47 \mathrm{~g}$ of carbohydrates $/ 100 \mathrm{~g}$ of gel, liquid fraction, and bagasse respectively. Uronic acids and malic acid were hallmarks of gel $(15.80 \%$ and $18.17 \%$, respectively); whilst for bagasse the occurrence of lignin is to be highlighted. The total phenolic content of the liquid fraction was $43.30 \mathrm{mg}$ aloin $\mathrm{g}^{-1}$ extract, whereas the value of $I C_{50}$ was $7.66 \mathrm{mg} \mathrm{mL}^{-1}$; the first was significantly higher and the second was lower when compared to the corresponding values for the

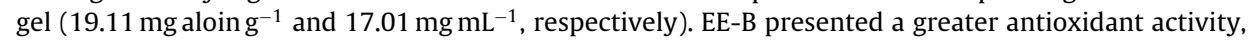
higher total phenolic content and better antifungal activity than AE-B. In all the treatments, the antifungal effect was concentration-dependent and varied according to the fungus genera used in the experiments. $A$. vera gel and liquid fraction as well as EE-B are interesting natural alternatives to control phytopathogenic fungi in industrial crops during pre- and postharvest stages.
\end{abstract}

(C) 2016 Elsevier B.V. All rights reserved.

\section{Introduction}

For many years, plants from different ecosystems have been collected and studied as a source of new bioactive compounds for a huge range of applications, such as antioxidants (Kuppusamy et al., 2016), drugs (Zengin et al., 2015), pesticides (Jasso de Rodríguez et al., 2011), among others.

\footnotetext{
* Corresponding author at: International Iberian Nanotechnology Laboratory, Av. Mestre José Veiga, 4715-330 Braga, Portugal. Tel.: +351 253140 112; fax: +351253140119.

** Corresponding author at: Universidad Autonoma Agraria Antonio Narro, Calzada Antonio Narro No. 1923, Colonia Buenavista, Saltillo, 25315 Coahuila, Mexico. Tel.: +52 844 4110296; fax: +528444110211.

E-mail addresses: miguelribeirocerqueira@gmail.com, miguel.cerqueira@inl.int (M.A. Cerqueira), dianajassocantu@yahoo.com.mx (D. Jasso de Rodríguez).
}

Postharvest damages of fruits and vegetables are often caused by colonization of various microorganisms, reducing their shelf life as well as their market value. In developing countries postharvest losses reach more than $40 \%$, being these losses even higher in the storage stage than those occurring in the field (Flores-López et al., 2015). The use of synthetic chemicals, such as pesticides, is the most common approach for disease control in different crops; however, the application of such chemicals has caused severe damage to the health and environment, and frequently their application is only allowed during preharvest (Jasso de Rodríguez et al., 2011). Their indiscriminate use has developed microorganism resistance to the most widely used synthetic pesticides, causing their exit of the market (Flores-López et al., 2015). Thence, the need for new pesticides with enhanced performance and having a low impact on the environment. Natural products represent an eco-friendly alternative to the use of chemicals for the management of diseases of fruit and vegetables. 
Aloe vera, from the Liliaceae family, is a perennial plant with lance shaped leaves formed by a thick epidermis (skin). It has traditionally been consumed as whole leaf in folk medicine for its beneficial health effects (Grindland and Reynolds, 1986). Its biological activity is broadly accepted and it is used for several medical, nutraceutical and cosmetic applications (Boudreau and Beland, 2006). The plant is divided in two components: a colourless mucilaginous pulp (gel) and a bitter yellow sap (exudate) (Grindland and Reynolds, 1986). The gel is the most studied and used part of $A$. vera due to its complex chemical composition. It is composed by carbohydrates being mostly acemannans polysaccharides (Lee et al., 2001), but also soluble sugars, organic acids, proteins, phenolic compounds, vitamins, minerals and aminoacids are present (Boudreau and Beland, 2006). The effectiveness of $A$. vera gel to control fungal growth has been extensively proven against Penicillium digitatum, $P$. expansum, Botrytis cinerea, and Alternaria alternata, among others (Castillo et al., 2010). Also, it has been incorporated into edible coatings (neat or in combination with other components) to extend the postharvest storage of strawberries (Sogvar et al., 2016) and apple slices (Chauhan et al., 2011).

The conventional methods for the extraction of $A$. vera gel are: (1) the traditional hand filleted pulp method, in which the entire gel is blended; and (2) the mechanical procedure characterized by a mechanical filleting followed by pressing, where the resulting gel can also be liquidized and filtered. The mechanical procedure also allows obtaining a liquid fraction (Jasso de Rodríguez et al., 2005). Recently, the interest for the liquid fraction has arisen, since it has shown to possess antifungal activity (Jasso de Rodríguez et al., 2005) and beneficial effects such as increasing the shelf life of blueberries has been reported (Vieira et al., 2016). However, there is limited information about the chemical composition and biological activities of $A$. vera liquid fraction.

The production process of $A$. vera fractions generates a large amount of solid wastes. These residues (bagasse) include the spikes, bases and tips removed from the leaves, and the skin resulting from the separation of the gel. Thus far, the bagasse has not been given any added value. Bioactive compounds can be extracted from the bagasse using organic solvents which are safe/less toxic (Cann, 2009), allowing an integral exploitation of $A$. vera. Therefore, the aims of this work were to (1) characterize the gel, liquid and bagasse of $A$. vera, (2) obtain extracts from bagasse, and (3) evaluate biological activity of gel, liquid and bagasse extracts in terms of antioxidant and antifungal activities on phytopathogenic fungi.

\section{Materials and methods}

\subsection{Materials}

Malic acid was supplied from Riedel-de Haën (Germany), citric acid anhydrous from J. T. Baker (USA), formic acid from Merck (Sweden), acetic acid from Sigma (USA) and lactic acid was supplied by Acros organics (USA). Galactose and mannose were obtained from Acros organics (USA), glucose from Fisher Scientific (USA), arabinose from Sigma (USA), galacturonic acid and xylose were supplied from Fluka (Slovakia). Sulfuric acid (95-98\%) and barium carbonate were purchased from Sigma (USA). Aloin of purity $>97 \%$ from Aloe barbadensis Miller leaves, 2,2-Diphenyl-1picrylhydrazyl (DPPH), buthylatedhydroxyanisole (BHA), sodium carbonate $\left(\mathrm{Na}_{2} \mathrm{CO}_{3}\right)$ and Folin-Ciocalteau (FC) reagent were purchased from Sigma (USA). Ethanol absolute and methanol were obtained from Fisher chemical (UK). Potato dextrose agar (PDA) was purchased from Difco (France) and potato dextrose broth (PDB) from Liofilchem (Italy). All samples, standards and eluents were prepared using demineralized Milli-Q water from Millipore, USA.

\subsection{Plant material and sample preparation}

Fresh whole Aloe vera leaves (four years old), supplied by Aloe Vera Ecológico (Alicante, Spain), were washed with water, immersed in a $2.0 \%$ sodium hypochlorite solution, and rinsed with distilled water. The leaves were weighed $(\mathrm{g})$, and measured for their length $(\mathrm{cm})$, thickness $(\mathrm{cm})$ and width $(\mathrm{cm})$. For each leaf the spikes, inferior and superior parts were removed before longitudinally slicing to separate the epidermis from the parenchyma (fillet). The fillet was pressed by means of a laboratory manual roll processor and filtered in order to separate the liquid fraction from the gel and the bagasse. The yields were determined and expressed as percentage of either the obtained gel or liquid fractions with respect to the entire leaf weight. The gel and liquid fractions were pasteurized by heating at $65{ }^{\circ} \mathrm{C}$ for $30 \mathrm{~min}$ and cooled immediately; this step was repeated three times (Jasso de Rodríguez et al., 2005). Afterwards, one part of the samples was lyophilized and another was stored at $-20^{\circ} \mathrm{C}$ until further analyses were performed.

\subsubsection{Preparation of the bagasse extracts}

The bagasse resulting from the separation of the gel and liquid fraction was dried at $40^{\circ} \mathrm{C}$, then ground to a particle size equivalent to mesh No. 50 prior to extraction. Approximately $5 \mathrm{~g}$ of dried bagasse was thoroughly extracted in a Soxhlet apparatus during $48 \mathrm{~h}$ with absolute ethanol or distilled water (ratio 1:20) at $99.4^{\circ} \mathrm{C}$ and $78.4^{\circ} \mathrm{C}$ for aqueous (AE-B) and ethanolic extract (EE$B)$, respectively. The crude extracts were subsequently filtered $\left(\mathrm{N}^{\circ} 1\right.$ Whatman filter paper) and concentrated in a rotary evaporator. The extracts were stored in the dark at $5^{\circ} \mathrm{C}$ until further use.

\subsection{Physico-chemical characterization of Aloe vera fractions}

All methodologies were conducted following the recommendations of the Official Method of Analysis (AOAC, 1990). The lipid content was determined gravimetrically by means of Soxhlet extraction (AOAC 960.39). The crude protein level was calculated by the Kjeldahl method with a conversion factor of 6.25 (AOAC 960.52 ). The ash content was evaluated by incineration in a muffle at $550^{\circ} \mathrm{C}$ (AOAC 923.03). Moisture content was determined using the method AOAC 934.06. The $\mathrm{pH}$ value was determined using a pH meter (Metrohm, Swiss). All measurements were carried out in triplicate.

\subsubsection{Organic acid analysis}

The extraction of organic acids from lyophilized gel and liquid fraction was carried out with water $\left(30 \mathrm{~min}\right.$ at $\left.60^{\circ} \mathrm{C}\right)$, following the method described by Bozzi et al. (2007). After the extraction process, solutions were filtered through a $0.45 \mu \mathrm{m}$ cellulose acetate membrane and organic acids (malic, citric, acetic and lactic acid) were determined by High-Performance Liquid Chromatography (HPLC). Chromatographic separation was performed using a Metacarb $87 \mathrm{H}$ column $(300 \times 7.8 \mathrm{~mm}$, Varian, USA $)$ under the following conditions: mobile phase $0.005 \mathrm{~mol} \mathrm{~L}^{-1} \mathrm{H}_{2} \mathrm{SO}_{4}$, flow rate $0.7 \mathrm{~mL} \mathrm{~min}^{-1}$, and column temperature $60^{\circ} \mathrm{C}$. The equipment used was a UV detector set at $210 \mathrm{~nm}$ (Jasco, Tokyo, Japan) and a Jasco AS-2057 Plus intelligent auto sampler(Jasco, Tokyo, Japan). The volume injected was $20 \mu \mathrm{L}$ per sample. The peaks obtained from each sample were identified and quantified through standard calibration curves.

\subsubsection{Polysaccharide analysis after hydrolysis}

Bagasse and lyophilized gel and liquid fraction were hydrolyzed via a two-step acid hydrolysis for polysaccharides quantification. Samples $\left(100 \mathrm{mg}\right.$ ) were pre-hydrolyzed in $\mathrm{H}_{2} \mathrm{SO}_{4} 72 \%$ by continuously stirring at $30^{\circ} \mathrm{C}$ during $1 \mathrm{~h}$; then post-hydrolysis was 
continued in $\mathrm{H}_{2} \mathrm{SO}_{4} 4.0 \%$ by autoclaving at $121^{\circ} \mathrm{C}$ for $1 \mathrm{~h}$. Samples were neutralized with barium carbonate, filtered through $0.45 \mu \mathrm{m}$ cellulose acetate membranes and analyzed by HPLC for glucose, xylose, galactose, arabinose and mannose using a 1100 series Hewlett-Packard chromatograph fitted with a refractive index detector operated at $50^{\circ} \mathrm{C}$ and $300 \times 7.8 \mathrm{~mm}$ CARBOsep CHO 682 column (Transgenomic, Glasgow, UK) operating at $80^{\circ} \mathrm{C}$. Distilled water was used as the mobile phase (flow rate $0.4 \mathrm{~mL} \mathrm{~min}^{-1}$ ). Uronic acids were colorimetrically determined using hydrolyzed samples and reported as total uronic acid (Ahmed and Labavitch, 1978).

\subsubsection{Analysis of free sugars}

Free sugars were analyzed by HPLC. Firstly, water-soluble monosaccharides and disaccharides were extracted with water (30 min at $70^{\circ} \mathrm{C}$ ) (Bozzi et al., 2007). Samples were subsequently filtered through a $0.45 \mu \mathrm{m}$ cellulose acetate membrane and analyzed using the CARBOsep CHO 682 column and the HPLC conditions already described in Section 2.3.2.

\subsection{Biological activity and phenolic composition}

\subsubsection{Phenolic composition}

Total phenolic content (TPC) was determined using a 96well microplate-adapted colorimetric assay using FC reagent as described by Meneses et al. (2013). Briefly, lyophilized gel and liquid fractions $(0.01 \mathrm{~g}$ ) were homogenized in $0.5 \mathrm{~mL}$ of methanol; the mixture was mixed using a vortex and extracted for $48 \mathrm{~h}$ at room temperature in darkness. To determine TPC from EE-B and AE-B the extracts $(0.01 \mathrm{~g})$ were re-suspended in ethanol and distillated water $(5 \mathrm{~mL})$, respectively. After homogenization, all samples were centrifuged at $12,000 \mathrm{~g}$ for $5 \mathrm{~min}$. Subsequently, $5 \mu \mathrm{L}$ of supernatant was mixed with $60 \mu \mathrm{L}$ of $\mathrm{Na}_{2} \mathrm{CO}_{3}$ solution $(7.5 \%, \mathrm{w} / \mathrm{v})$ and $15 \mu \mathrm{L}$ of FC reagent. Then $200 \mu \mathrm{L}$ of distilled water were added and solutions were mixed. Absorbance was measured using a spectrophotometric microplate reader (Synergy HT, Biotek, USA) at $700 \mathrm{~nm}$ after incubation at $60^{\circ} \mathrm{C}$ for $5 \mathrm{~min}$. A calibration curve was prepared using a standard solution of aloin $\left(0.2,0.4,0.6,0.8,1.0 \mathrm{mg} \mathrm{mL}^{-1}\right.$, $\left.R^{2}=0.9905\right)$. All experiments were performed in triplicate. The total phenolic content was determined as aloin equivalents and values are expressed as $\mathrm{mg}$ of aloin per $\mathrm{g}$ of extract.

\subsubsection{Antioxidant activity}

Free radical scavenging activity of gel, liquid and bagasse extracts (EE-B and AE-B) was determined using the DPPH method with some modifications (Pinheiro et al., 2015). BHA was used as antioxidant of reference and ethanol as control. Briefly, $0.2 \mathrm{~mL}$ of ethanol and $0.3 \mathrm{~mL}$ of the sample dissolved in ethanol (concentrations ranging from 0.05 to $30 \mathrm{mg} \mathrm{mL}^{-1}$ ) were mixed with $2.5 \mathrm{~mL}$ of DPPH $\left(60 \mu \mathrm{mol} \mathrm{L}^{-1}\right.$ in ethanol) to achieve a final volume of $3.0 \mathrm{~mL}$. The solution was mixed in a vortex and kept at room temperature for $30 \mathrm{~min}$ in the dark. Then, $0.2 \mathrm{~mL}$ of each sample was transferred into a 96-well microplate to measure absorbance at $515 \mathrm{~nm}$ (BiotekSinergy II, USA) and antioxidant activity was expressed as percentage DPPH-scavenging activity relative to the control, using the following equation:

\%Radical scavenging $(R S A)=\frac{\left(A_{\text {control }}-A_{\text {sample }}\right)}{A_{\text {control }}} \cdot 100$

where $A_{\text {control }}$ represents the absorbance value of the control sample and $A_{\text {sample }}$ represents the absorbance value of the analyzed sample. The $I C_{50}$ value was calculated as the concentration required to obtain a $50 \%$ of inhibition of radical scavenging activity $(R S A) . I C_{50}$ was determined from a graph of $R S A(\%)$ against sample concentration $\left(\mathrm{mg} \mathrm{mL}^{-1}\right)$. All experiments were performed in triplicate.

\subsubsection{Antifungal activity}

Penicillium expansum (MUM 02.14) and Botrytis cinerea (MUM 10.138) were obtained from MUM (Micoteca da Universidade do Minho, Braga, Portugal). The fungi were routinely cultured on PDA at $25^{\circ} \mathrm{C}$ for $7-14 \mathrm{~d}$; the spores were collected and diluted with sterile water until suspensions reached a spore concentration of $10^{4} \mathrm{~mL}^{-1}$.

Antifungal activity of gel and liquid fractions at 3 doses (0.1, 1.0 and $50 \%, v / v$ ) and bagasse extracts (EE-B and AE-B) at 3 doses $(50,100$ and $500 \mathrm{ppm}, \mathrm{w} / \mathrm{v})$ were evaluated following the procedure reported by Kouassi et al. (2012), with some modifications. $100 \mu \mathrm{L}$ of each concentration were pipetted into a sterile 96-well microplate. Each well was inoculated with a $100 \mu \mathrm{L}$ aliquot of fungal inoculum to reach a final volume of $200 \mu \mathrm{L}$. A positive control was carried out by mixing $100 \mu \mathrm{L}$ of sterile PDB with $100 \mu \mathrm{L}$ of each fungal suspension. The negative control of each group of replicates was a non-inoculated medium. In order to ensure that the solvent did not interfere with the test, controls only with water (for AEB) and absolute ethanol (for EE-B) were carried out. Fungal growth was monitored spectrophotometrically at $530 \mathrm{~nm}$ (BiotekSinergy II, USA) by measuring optical density (OD) during $72 \mathrm{~h}$ (at $24 \mathrm{~h}$ intervals) and incubation at $25 \pm 2{ }^{\circ} \mathrm{C}$. Percentage of growth inhibition was determined using the following equation:

Inhibition $(\%)=\left\lfloor\frac{\left(O D_{\text {control }}-O D_{\text {sample }}\right)}{O D_{\text {control }}}\right\rfloor \cdot 100$

where $O D_{\text {sample }}$ represents the optical density of the each treatment and $O D_{\text {control }}$ represents the optical density of the control. Experiments were replicated three times per treatment.

\subsection{Statistical analyses}

Data analyses were subjected to analysis of variance (ANOVA) using FAUANL software (Olivares, 1994). Fisher's Least Significance Difference (LSD) multiple comparison test was performed to detect significant differences $(p<0.05)$ between treatments.

\section{Results and discussion}

\subsection{Leaf characteristics and yields}

The characteristics of the leaves utilized in this work were found quite in agreement with the leaf dimensions $(30-60 \mathrm{~cm}$ in length, $5-12 \mathrm{~cm}$ wide at the base and $0.8-3 \mathrm{~cm}$ thick) and weight (364-455 g) reported for A. vera (Añez and Vásquez, 2005; Rodríguez-García et al., 2007) (Table 1). The gel and bagasse were separated from the liquid fraction, obtaining extraction yields of $15.76 \%, 33.00 \%$, and $51.20 \%$, respectively. The extraction yield of $A$. vera gel is generally around ca. 60\% (Zapata et al., 2013), although these yields are considered without separation of liquid fraction and are directly influenced by the water content of the leaves during planting (Rodríguez-García et al., 2007) and the method of extraction. The yields obtained are in the range reported by Hernández-Cruz et al. (2002), which performed the separation of gel and liquid fractions using a laboratory roll processor. The authors reported extraction yields of $20 \%$ and $40 \%$ for gel and liquid fractions, respectively. The $\mathrm{pH}$ values found in the gel and liquid fractions ( $\mathrm{pH}$ of 4.3 and 4.9 , respectively) are within the range reported previously for $A$. vera gel ( $\mathrm{pH}$ of $4.58-5.30$ ) (Zapata et al., 2013).

\subsection{Chemical composition}

The mean values and standard deviations of the composition results obtained for $A$. vera fractions in an oven-dry basis are pre- 
Table 1

Leaf dimensions, weight and extraction yield of Aloe vera for gel, liquid and bagasse.

\begin{tabular}{|c|c|c|c|c|c|c|c|}
\hline \multicolumn{4}{|c|}{ Leaf dimensions $(\mathrm{cm})$} & \multicolumn{4}{|l|}{ Yield (\%) } \\
\hline Length & Width at base & Width at half & Thickness & Weight (g) & Gel & Liquid & Bagasse \\
\hline $36.80( \pm 6.14)$ & $10.15( \pm 0.63)$ & $8.55( \pm 0.72)$ & $2.63( \pm 0.40)$ & $484.34( \pm 46.10)$ & $15.76( \pm 4.00)$ & $51.20( \pm 5.20)$ & $33.00( \pm 5.00)$ \\
\hline
\end{tabular}

Values reported are the mean \pm standard deviation $(n=10)$.

Table 2

Chemical characterization of Aloe vera fractions (results are expressed as percentages on dry matter basis).

\begin{tabular}{llll}
\hline & Gel & Liquid & Bagasse \\
\hline Total solids & $1.38 \pm 0.36$ & $0.65 \pm 0.01$ & $92.33 \pm 1.31$ \\
Soluble sugars (Glucose) & $7.71 \pm 0.14$ & $10.37 \pm 1.46$ & n.d. \\
Proteins & $3.17 \pm 0.12$ & $3.28 \pm 0.11$ & $4.78 \pm 0.10$ \\
Lipids & $0.66 \pm 0.03$ & $0.53 \pm 0.10$ & $2.08 \pm 0.11$ \\
Ashes & $0.43 \pm 0.06$ & $0.70 \pm 0.00$ & $13.92 \pm 0.39$ \\
Uronic acids & $15.80 \pm 0.78$ & $2.75 \pm 0.55$ & $19.81 \pm 2.25$ \\
Polysaccharides & & & \\
$\quad$ Glucose & $16.78 \pm 0.40$ & $13.01 \pm 0.11$ & $14.77 \pm 0.52$ \\
Mannose & $14.90 \pm 0.35$ & $13.03 \pm 0.07$ & $12.09 \pm 1.47$ \\
Galactose & $0.92 \pm 0.52$ & $0.36 \pm 0.00$ & $2.40 \pm 0.95$ \\
$\quad$ Xylose & $0.57 \pm 0.14$ & n.d. & $0.40 \pm 0.07$ \\
Arabinose & $0.77 \pm 0.32$ & $0.57 \pm 0.00$ & $0.84 \pm 0.16$ \\
Lignin & n.d. & n.d. & $8.16 \pm 0.33$ \\
Organic acids & & & \\
$\quad$ Acetic & $3.65 \pm 0.32$ & $2.99 \pm 0.07$ & $2.23 \pm 0.08$ \\
Malic & $18.17 \pm 2.85$ & $4.07 \pm 1.11$ & n.d. \\
Citric & $0.36 \pm 0.10$ & $0.92 \pm 0.32$ & n.d. \\
Lactic & n.d. & $19.53 \pm 1.04$ & n.d. \\
\hline
\end{tabular}

n.d.: not detected.

Values reported are the mean \pm standard deviation.

sented in Table 2. The major feature of both gel and liquid fraction is their high water content with $98.62 \%$ and $99.35 \%$, respectively. In contrast, the bagasse is constituted by higher content of solids. Lipids were a minor component for all $A$. vera fractions and are within the range reported previously for $A$. vera gel $(0.08-0.19 \%)$ (Zapata et al., 2013) and skin (2.71\%) (Femenia et al., 1999). Also, proteins were in agreement with the values reported for gel (3.72\%) (Vega-Gálvez et al., 2011a) and skin (6.33\%) (Femenia et al., 1999). Ashes were a minor fraction for gel and liquid fraction with less than $1.5 \%$, whilst bagasse shown relative higher ash (13.92\%) and lipids (2.08\%) contents. Previous works have reported higher ashes content for gel (17.64-23.61\%) than those found in this work (VegaGálvez et al., 2011a; Femenia et al., 1999), whilst for bagasse the results are in agreement with the values reported by Femenia et al. (1999) for skin of $A$. vera (13.46\%). The presence of minerals in $A$. vera is essential for the proper functioning of various enzymes systems in different metabolic pathways and few are antioxidants; also, minerals such as potassium have been associated with the regulation of the healing properties of $A$. vera (Surjushe et al., 2008). Thence, it appears reasonable to speculate that higher content of minerals can be concentrated in the skin with the aim of improving the resistance of the plant to biotic and abiotic stresses (i.e. attack by microorganisms and high water stress).

The sum of carbohydrates and lignin found in the gel, liquid fraction and bagasse represented $57.45 \%, 40.09 \%$ and $56.86 \%$ of the total components, respectively (Table 2). Lignin was only detected in the bagasse, since the occurrence of secondary lignified walls leads to cross-linking of cell wall polysaccharides causing an increase in the hardening of that tissue (Femenia et al., 1999). Also, it is known that lignin is an important source of polyphenolic compounds available from natural biomass feedstocks (Jung et al., 2015).

As can be seen in Table 2 for all $A$. vera fractions, glucose and mannose were found as the major constituents in a ratio of ca 1:1. These sugars have been reported in various ratios as components of polysaccharides occurring in the $A$. vera gel, e.g. acetyled glucomannans (Lee et al., 2001). It has been reported that $A$. vera gel is formed by linear polymers with no branching and having 1,4 glycosidic linkages with glucose and mannose (Lee et al., 2001). The presence of higher amounts of uronic acids followed by lower amounts of galactose confirms the occurrence of pectic polysaccharides in gel and bagasse. Rodríguez-González et al. (2011) reported that the large presence of galacturonic acid units and the lower amounts of galactose and arabinose are associated to the presence of homogalacturonans, and minor amounts of rhamnogaluctoronans with a low degree of branching. This was confirmed by Gentilini et al. (2014), who extracted pectin from A. vera gel with high content of galacturonic acid and a low degree of esterification. The occurrence of relatively small amounts of xylose in gel and bagasse can be related to the presence of hemicellulosic xyloglucans (Femenia et al., 2003). On the other hand, the liquid fraction only presented traces of galactose and arabinose (no xylose was detected) and had the lowest values of uronic acid units (2.75\%), indicating a lower concentration of pectic polysaccharides in this fraction. This fact shows than one of the most important differences between A. vera gel and liquid fraction are the occurrence of different concentrations of pectin, which in presence of calcium can form an intra-cellular "cement" that provides firmness to the tissues and can thus be related to the gel-like behavior of the gel fraction (Alonso et al., 1995).

On the other hand, the main soluble sugar detected in $A$. vera fractions was glucose, being the values higher in the liquid fraction (10.37\%) when compared with those obtained for gel (7.71\%). Bozzi et al. (2007) detected also other free sugars in $A$. vera fresh gel such as fructose $(5.30 \%)$, sucrose $(0.16 \%)$ and galactose $(0.05 \%)$, but in lower concentrations than glucose (11.85\%).

The measurement of organic acids (e.g. malic acid) is used as a quality parameter in $A$. vera processing; however, their concentrations in Aloe vera fractions can vary depending on biological variability and the manufacturing process (Bozzi et al., 2007). The organic acid profile detected for $A$. vera gel was characterized mainly by the presence of high amounts of malic acid (18.17\%), whilst in the liquid fraction, lactic acid was found in higher concentration (19.53\%) (Table 2). Malic acid is considered as an indicator of gel freshness and quality (Rodríguez et al., 2010) and is formed in A. vera gel as a result of crassulacean acid metabolism (CAM), being present usually in the range of $11.10 \%$ and $40.40 \%$ (Jiao et al., 2010). In contrast, the presence of other organic acids can suggest possible microbial and enzymatic degradation (e.g. lactic, fumaric, formic, succinic, and acetic acids) (Rodríguez et al., 2010). Since malic acid is susceptible to bacterial degradation into lactic acid (Garcia et al. 1992), the lower value of malic acid and highest values of lactic acid in liquid fraction are indicators of bacterial degradation of the sample.

\subsection{Phenolic compounds and antioxidant activity}

The antioxidant activity of $A$. vera gel, liquid fraction and bagasse extracts (EE-B and AE-B) is shown in terms of $I C_{50}$, which corresponds to the concentration required to achieve $50 \%$ of inhibition of the oxidation (Table 3). In general, EE-B had the lowest value of $I C_{50}\left(0.34 \mathrm{mg} \mathrm{mL}^{-1}\right)$ when compared with the gel and liquid frac- 
Table 3

Total phenolic content (TPC) and $I C_{50}$ of gel, liquid fraction and bagasse extracts of Aloe vera; $I C_{50}$ values for BHA are given for comparison.

\begin{tabular}{lll}
\hline Sample & $T P C\left(\mathrm{mg}\right.$ aloin ${ }^{-1}$ extract $)$ & $I C_{50}\left(\mathrm{mg} \mathrm{mL}^{-1}\right)$ \\
\hline Gel & $19.11 \pm 0.91^{\mathrm{d}}$ & $17.01 \pm 0.77^{\mathrm{a}}$ \\
Liquid & $43.30 \pm 1.66^{\mathrm{c}}$ & $7.66 \pm 0.71^{\mathrm{b}}$ \\
AE-B & $88.37 \pm 4.41^{\mathrm{b}}$ & $0.40 \pm 0.01^{\mathrm{c}}$ \\
EE-B & $454.10 \pm 4.51^{\mathrm{a}}$ & $0.34 \pm 0.01^{\mathrm{c}}$ \\
BHA & & $0.07 \pm 0.01^{\mathrm{c}}$ \\
\hline
\end{tabular}

Values in the same column followed by different letters are statistically different $(p<0.05)$.

Values reported are the mean \pm standard deviation.

tion ( $p<0.05)$. However, there are no significant differences $(p>0.05)$ between the $I C_{50}$ of EE-B and AE-B, whose recovery yields were of $9.62 \pm 0.45 \%$ and $47.41 \pm 5.10 \%$, respectively.

Previous works have reported the relation between the TPC, RSA and $I C_{50}$ values, showing a positive correlation of higher values of TPC with the antioxidant activity (Cerqueira et al., 2010). In this work, such tendency was also observed since EE-B, that exhibited higher antioxidant activity, also presented a higher TPC content ( $454.10 \pm 4.51 \mathrm{mg}$ aloin $\mathrm{g}^{-1}$ extract) than the other samples. These polyphenolic compounds could be extracted from bagasse due to the affinity that exists between ethanol (polar solvent) and polar structures (Jasso de Rodríguez et al., 2011).

The liquid fraction had a significantly lower $I C_{50}$ value than the gel $(p<0.05)$, being these results comparable with those reported by Vieira et al. (2016) for liquid and gel (7.76 and $22.37 \mathrm{mg} \mathrm{mL}^{-1}$, respectively). This can be associated with the fact that liquid fraction presented values of TPC 2-fold higher $(43.30 \pm 1.66 \mathrm{mg}$ aloin $\mathrm{g}^{-1}$ extract) than gel $\left(19.11 \pm 0.91 \mathrm{mg}^{2}\right.$ aloin $\mathrm{g}^{-1}$ extract).

It has been demonstrated that the amount of phenolic compounds can vary among different forms of $A$. vera (e.g. aloe exudate, gel, skin and flowers) (López et al., 2013) and the age of the plant (Rodríguez et al., 2010), therefore exhibiting different antioxidant activities. Previous studies regarding the content of phenolic compounds in the liquid fraction were not found; however, the antioxidant activity of gel found in the present work is in agreement with the work of Vega-Gálvez et al. (2011b). For the gel, the antioxidant activity has been attributed to Aloe polysaccharides (Chun-hui et al., 2007) and vitamins C and E (Rodríguez et al., 2010).

\subsection{Antifungal activity}

The inhibition effect of $A$. vera gel and liquid fraction as a function of concentration is presented in Fig. 1. For both fungi, the antifungal activity was concentration-dependent, being higher $(100 \%$ of mean inhibition) when the highest concentration (50\%) was evaluated. A higher inhibition effect was observed on P. expansum than $B$. cinerea at lower concentrations of gel and liquid fraction $(0.1 \%$ and $1.0 \%$ ). The results are in agreement with previous reports in which the antifungal effect of $A$. vera gel is related with the fungal genera, as reported by Nabigol and Asghari (2013) that described a higher antifungal activity of $A$. vera gel against $P$. digitatum than against Aspergillus niger, whereas Castillo et al. (2010) reported higher growth inhibition for $P$. digitatum than for $B$. cinerea.

Otherwise, it was observed a greater effect of gel when it is compared with liquid fraction after 48 and $72 \mathrm{~h}$ on $P$. expansum. It can be associated with the fact that the gel presented a higher content of malic acid (Table 2) than the liquid fraction; this compound has been demonstrated to have antimicrobial activity (RaybaudiMassilia et al., 2008). For B. cinerea a similar behavior of the gel and liquid fraction was observed; although the liquid fraction presented a higher inhibition $(p<0.05)$ against $B$. cinerea at $24 \mathrm{~h}$ for a lower dose when compared with the gel, this effect was not observed at $72 \mathrm{~h}$ (Fig. 1b). Jasso de Rodríguez et al. (2005) reported a higher
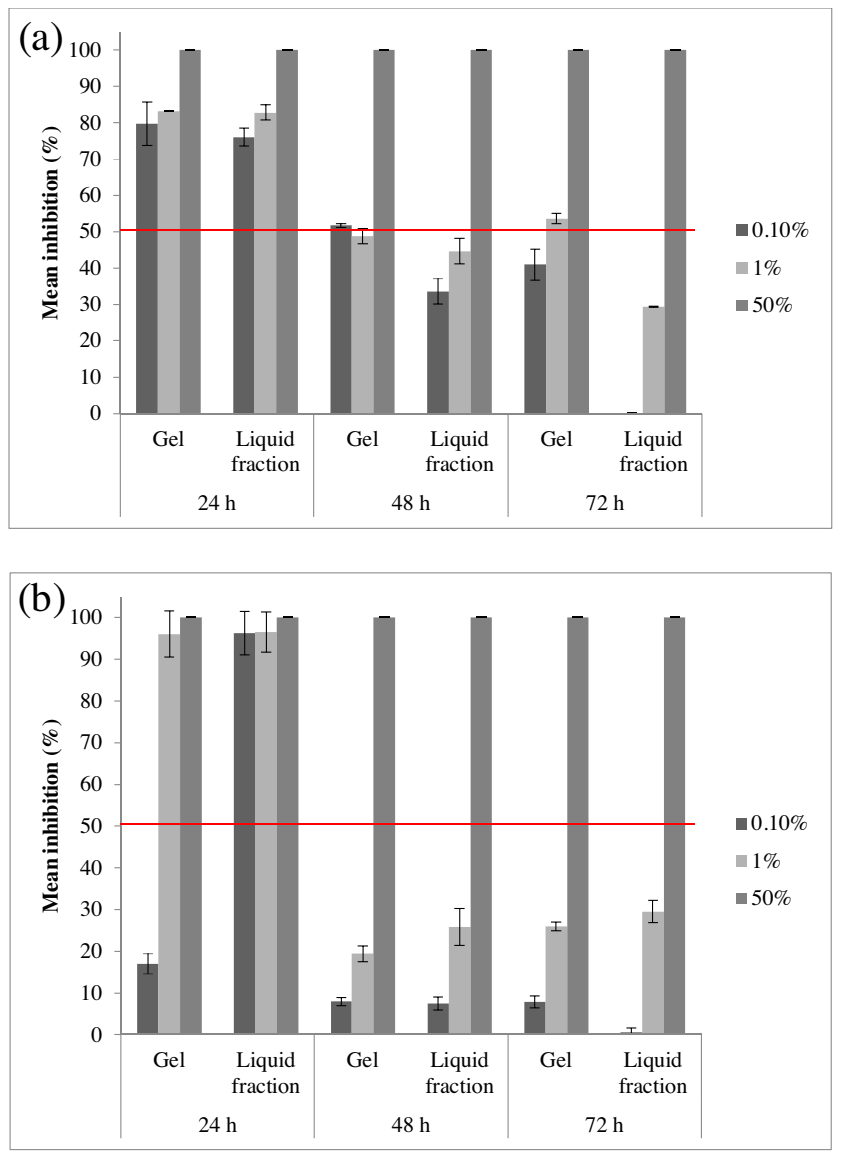

Fig. 1. Mean inhibition effect (\%) of gel and liquid fraction on (a) Penicillium expansum and (b) Botrytis cinerea for 24, 48 and $72 \mathrm{~h}$ of incubation.

inhibitory effect of $A$. vera liquid fraction against Colletotrichum coccodes and Rhizoctonia solani (22\% and $28 \%$, respectively) than that observed for the gel fraction; the $A$. vera gel showed a higher growth inhibition (53\%) of Fusarium oxysporum than the liquid fraction (38\%). In the literature, the antifungal activity of gel of Aloe species has been attributed to diverse bioactive compounds, such as aloe-emodin and aleonin, showing control of growth of $A$. niger, Cladosporium herbarum and F. moniliforme (Ali et al., 1999). Meanwhile, Zapata et al. (2013) evidenced the positive correlation of antifungal activity with the aloin content in gel of $A$. ferox, A. mitriformis, A. sapononaria and $A$. vera. However, as far as we are aware, not reports about liquid fraction composition and its relation with its antifungal activity were found. According to our results, the antifungal activity of liquid fraction could be related with the higher $(p<0.05)$ amount of TPC when compared to the gel (Table 3).

The antifungal effect of ethanolic and aqueous extracts of $A$. vera bagasse (EE-B and AE-B, respectively) is presented in Fig. 2. Both extracts have shown concentration-dependent antifungal activity. AE-B has shown an inhibition effect of up to $50 \%$ at 24 and $48 \mathrm{~h}$ on both fungi, but no effect was observed at $72 \mathrm{~h}$ on $B$. cinerea; whereas on $P$. expansum the inhibition decreased at $72 \mathrm{~h}$ (40-50\%). The AE-B showed a lower inhibitory effect, which might be associated with the extracting capacity of the solvent (water) and the concentration of phytochemicals recovered in the extract. Several studies have reported that aqueous extracts do not have large inhibition against fungi, since most of the active phytochemicals are better dissolved in alcoholic solvents than in water (Moorthy et al., 2013). EE-B presented higher inhibition (up to 50\%) than AE-B and this effect was maintained during $72 \mathrm{~h}$, suggesting a better stability of this extract. EE-B showed also a similar effect on both phytopathogenic fungi. 

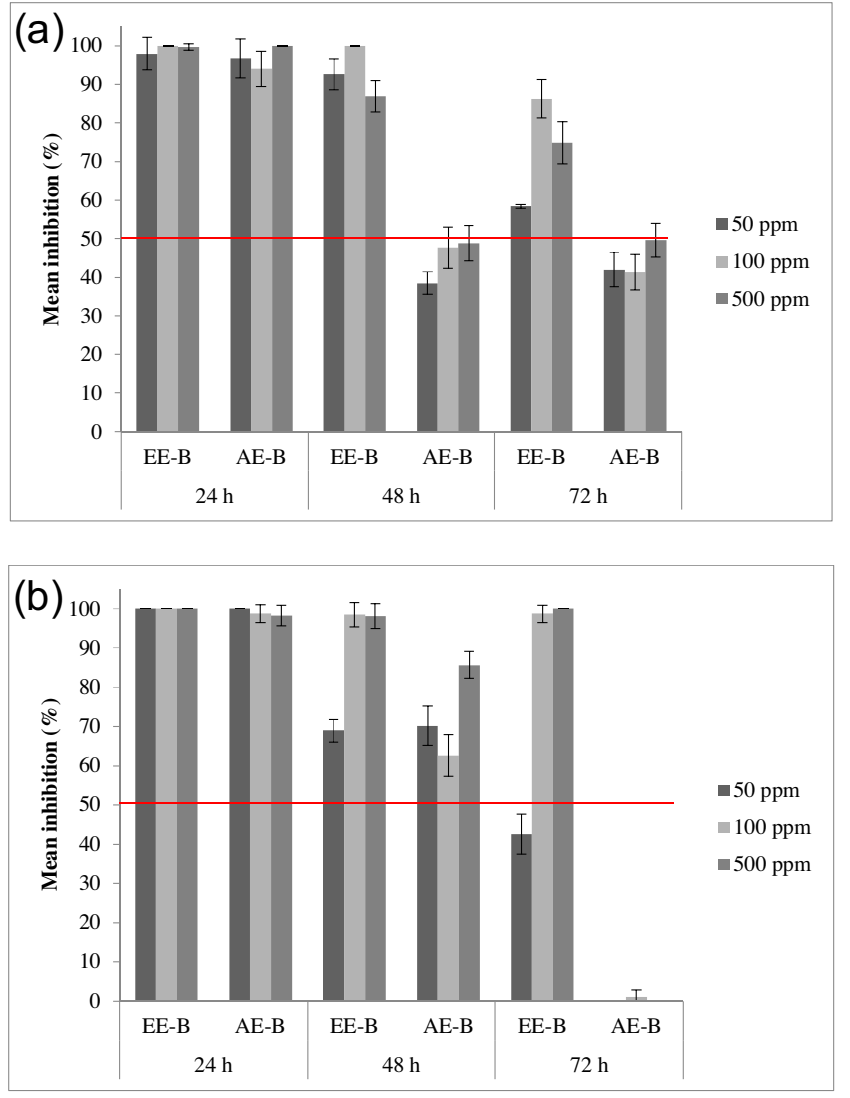

Fig. 2. Mean inhibition effect (\%) of ethanolic (EE-B) and aqueous (AE-B) bagasse extracts on (a) Penicillium expansum and (b) Botrytis cinerea for 24,48 and $72 \mathrm{~h}$ of incubation.

It has been demonstrated that the effectiveness of the extracts depends on the nature of the solvent, as well as on the plant species and on the fungus evaluated (Ali et al., 1999; Jasso de Rodríguez et al., 2011). The results obtained can point to the conclusion that the use of ethanol as solvent allows higher recovery of polyphenolic molecules (Table 3 ) with strong antifungal activity from the bagasse of $A$. vera.

\section{Conclusions}

Gel and liquid fraction from $A$. vera and the resulting bagasse of the separation process were separately characterized and their antifungal and antioxidant properties were evaluated. Also, ethanolic and aqueous extracts from bagasse were obtained. Glucose and mannose were the main sugars present in the three $A$. vera fractions, in a relation of ca. $1: 1$. Bagasse was characterized by the presence of lignin and higher content of ashes; in addition, it presented uronic acids related with pectic polysaccharides. The main difference between gel and liquid fraction was the occurrence of higher amounts of uronic acids and malic acid in the gel. The liquid fraction presented a significantly better $I C_{50}$ than the gel, and this can be attributed to the higher amounts of the TPC. In general the gel, liquid fraction and bagasse extracts presented high antioxidant activity, being that the ethanolic extract of bagasse reported the highest activity among all the extracts tested. Antifungal activities against $P$. expansum and $B$. cinerea were exhibited for both $A$. vera fractions (gel and liquid), being concentration-dependent and varying according to the fungus genera. For bagasse extracts the inhibition effect also was concentration-dependent, where EE$B$ has shown a better antifungal activity than AE-B, which may be related with the higher amount of TPC detected in EE-B.
A. vera fractions can represent an interesting natural alternative for formulations aiming at controlling phytopathogenic fungi in industrial crops during pre- and postharvest stages. This is the first scientific report of the phenolic composition and antioxidant activity of the liquid fraction of $A$. vera and antioxidant and antifungal activity of bagasse.

\section{Acknowledgements}

María L. Flores-López thanks Mexican Science and Technology Council (CONACYT, Mexico) for PhD fellowship support (CONACYT grant number: 215499/310847) and COECTY-Coahuila State Government (COAH-2016-C11-A04). Aloia Romaní was supported by Xunta de Galicia fellowship (Plan I2C, 2014). This study was supported by the Portuguese Foundation for Science and Technology (FCT) under the scope of the strategic funding of UID/BIO/04469/2013 unit and COMPETE 2020 (POCI-010145-FEDER-006684) and of the Project RECI/BBB-EBI/0179/2012 (FCOMP-01-0124-FEDER-027462).

\section{References}

Ahmed, A.E.R., Labavitch, J.M., 1978. A simplified method for accurate determination of cell wall uronide content. J. Food Biochem. 1, 361-365, http://dx.doi.org/10.1111/j.1745-4514.1978.tb00193.x.

Ali, M.I.A., Shalaby, N.M.M., Elgamal, M.H.A., Mousa, A.S.M., 1999. Antifungal effects of different plant extracts and their major components of selected aloe species. Phytother. Res. 13, 401-407, http://dx.doi.org/10.1002/(SICI)10991573(199908/09)13:5<401:AID-PTR515>3.0.CO;2-K.

Alonso, J., Rodriguez, T., Canet, W., 1995. Effect of calcium pretreatments on the texture of frozen cherries. Role of pectinesterase in the changes in the pectic materials. J. Agric. Food Chem. 43, 1011-1016, http://dx.doi.org/10.1021/ jf00052a031.

Añez, B., Vásquez, J., 2005. Effect of population density on growth and yield of aloe (Aloe barbadensis M.). Rev. Fac. Agron. 22, 1-12.

AOAC, 1990. Assoaciation of Official Analytical Chemists. In: Official, M. (Ed.) AOAC, Washington, DC, USA.

Boudreau, M.D., Beland, F.A., 2006. An evaluation of the biological and toxicological properties of Aloe barbadensis (Miller), Aloe vera. J. Environ. Sci. Health C: Environ. Carcinog. Ecotoxicol. Rev. 24, 103-154, http://dx.doi.org/10.1080/ 10590500600614303.

Bozzi, A., Perrin, C., Austin, S., Arce vera, F., 2007. Quality and authenticity of commercial Aloe vera gel powders. Food Chem. 103, 22-30, http://dx.doi.org 10.1016/j.foodchem.2006.05.061.

Cann, M.C., 2009. Greening the chemistry lecture curriculum: now is the time to infuse existing mainstream textbooks with green chemistry. ACS Symp. Ser. 1011, 93-102, http://dx.doi.org/10.1021/bk-2009-1011.ch006.

Castillo, S., Navarro, D., Zapata, P.J., Guillén, F., Valero, D., Serrano, M. Martínez-Romero, D., 2010. Antifungal efficacy of Aloe vera in vitro and its use as a preharvest treatment to maintain postharvest table grape quality. Postharvest Biol. Technol. 57, 183-188, http://dx.doi.org/10.1016/j. postharvbio.2010.04.006.

Cerqueira, M.A., Souza, B.W.S., Martins, J.T., Teixeira, J.A., Vicente, A.A., 2010. Seed extracts of Gleditsia triacanthos: functional properties evaluation and incorporation into galactomannan films. Food Res. Int. 43, 2031-2038, http:// dx.doi.org/10.1016/j.foodres.2010.06.002.

Chauhan, O.P., Raju, P.S., Singh, A., Bawa, A.S., 2011. Shellac and aloe-gel-based surface coatings for maintaining keeping quality of apple slices. Food Chem. 126, 961-966, http://dx.doi.org/10.1016/j.foodchem.2010.11.095.

Chun-hui, L., Chang-hai, W., Zhi-liang, X., Yi, W., 2007. Isolation, chemical characterization and antioxidant activities of two polysaccharides from the gel and the skin of Aloe barbadensis Miller irrigated with sea water. Process Biochem. 42, 961-970, http://dx.doi.org/10.1016/j.procbio.2007.03.004.

Femenia, A., Sánchez, E.S., Simal, S., Rosselló, C., 1999. Compositional features of polysaccharides from Aloe vera (Aloe barbadensis Miller) plant tissues. Carbohydr. Polym. 39, 109-117, http://dx.doi.org/10.1016/S01448617(98)00163-5.

Femenia, A., García-Pascual, P., Simal, S., Roselló, C., 2003. Effects of heat treatment and dehydration on bioactive polysaccaride acemannan and cell wall polymers from Aloe barbadensis Miller. Carbohydr. Polym. 51, 397-405, http://dx.doi.org/ 10.1016/j.carbpol.2011.06.084.

Flores-López, M.L., Cerqueira, M.A., Jasso de Rodríguez, D., Vicente, A.A., 2015. Perspectives on utilization of edible coatings and nano-laminate coatings for extension of postharvest storage of fruits and vegetables. Food Eng. Rev., http://dx.doi.org/10.1007/s12393-015-9135-x.

Garcia, M.J., Zuniga, M., Kobayashi, H., 1992. Energy production from L-malic acid degradation and protection against acidic external $\mathrm{pH}$ in Lactobacillus plantarum CECT 220. J. Gen. Microbiol. 138, 2519-2524, http://dx.doi.org/10. 1099/00221287-138-12-2519. 
Gentilini, R., Bozzini, S., Munarin, F., Petrini, P., Visai, L., Tanzi, M.C., 2014. Pectins from Aloe vera: extraction and production of gels for regenerative medicine. J. Appl. Polym. Sci. 131, 1-9, http://dx.doi.org/10.1002/app.39760.

Grindland, D., Reynolds, T., 1986. The Aloe vera phenomenon: a review of the properties and modern uses of the leaf parenchyma gel. J. Ethnopharmacol. 16, $117-151$.

Hernández-Cruz, L.R., Rodríguez-García, R., Jasso de Rodríguez, D. Angulo-Sánchez, J.L., 2002. Aloe vera response to plastic mulch and nitrogen. In: Janick, J. Whipkey (Ed.), Trends new Crop. new uses pp. 570-574.

Jasso de Rodríguez, D., Hernández-Castillo, D., Rodríguez-García, R. Angulo-Sánchez, J.L., 2005. Antifungal activity in vitro of Aloe vera pulp and liquid fraction against plant pathogenic fungi. Ind. Crops Prod. 21, 81-87, http://dx.doi.org/10.1016/j.indcrop.2004.01.002.

Jasso de Rodríguez, D., Rodríguez García, R., Hernández Castillo, F., Aguilar González, C.N., Sáenz Galindo, A., Villarreal Quintanilla, J.A., Moreno Zuccolotto, L.E., 2011. In vitro antifungal activity of extracts of Mexican Chihuahuan Desert plants against postharvest fruit fungi. Ind. Crops Prod. 34, 960-966, http://dx.doi.org/10.1016/j.indcrop.2011.03.001.

Jiao, P., Jia, Q., Randel, G., Diehl, B., Weaver, S., Milligan, G., 2010. Quantitative $1 \mathrm{H}-\mathrm{NMR}$ spectrometry method for quality control of Aloe vera products. J. AOAC Int. 93, 842-848.

Jung, K.A., Woo, S.H., Lim, S.R., Park, J.M., 2015. Pyrolytic production of phenolic compounds from the lignin residues of bioethanol processes. Chem. Eng. J. 259, 107-116, http://dx.doi.org/10.1016/j.cej.2014.07.126.

Kouassi, K.H.S., Bajji, M., Jijakli, H., 2012. The control of postharvest blue and green molds of citrus in relation with essential oil-wax formulations, adherence and viscosity. Postharvest Biol. Technol. 73, 122-128, http://dx.doi.org/10.1016/j. postharvbio.2012.06.008.

Kuppusamy, S., Thavamani, P., Megharaj, M., Nirola, R., Lee, Y.B., Naidu, R., 2016. Assessment of antioxidant activity, minerals, phenols and flavonoid contents of common plant/tree waste extracts. Ind. Crops Prod., http://dx.doi.org/10. 1016/j.indcrop.2015.12.060.

Lee, J.K., Lee, M.K., Yun, Y.-P., Kim, Y., Kim, J.S., Kim, Y.S., Kim, K., Han, S.S., Lee, C.-K. 2001. Acemannan purified from Aloe vera induces phenotypic and functional maturation of immature dendritic cells. Int. Immunopharmacol. 1, 1275-1284, http://dx.doi.org/10.1016/S1567-5769(01)00052-2.

López, A., De Tangil, M.S., Vega-Orellana, O., Ramírez, A.S., Rico, M., 2013. Phenolic constituents, antioxidant and preliminary antimycoplasmic activities of leaf skin and flowers of Aloe vera (L.) Burm. f. (syn. A. barbadensis Mill.) from the Canary Islands (Spain). Molecules 18, 4942-4954, http://dx.doi.org/10.3390/ molecules18054942.

Meneses, N.G.T., Martins, S., Teixeira, J.A., Mussatto, S.I., 2013. Influence of extraction solvents on the recovery of antioxidant phenolic compounds from brewer's spent grains. Sep. Purif. Technol. 108, 152-158, http://dx.doi.org/10. 1016/j.seppur.2013.02.015.

Moorthy, K.K., Subramaniam, P., Senguttuvan, J., 2013. In vitro antifungal activity of various extracts of leaf and stem parts of Solena amplexicaulis (Lam.) Gandhi. Int. J. Pharm. Pharm. Sci. 5, 745-747.

Nabigol, A., Asghari, A., 2013. Antifungal activity of Aloe vera gel on quality of minimally processed pomegranate arils. Int. J. Agron. Plant Prod. 4, 833-838.
Olivares, S.E., 1994. Paquete de diseños experimentales. FAUANL. Versión 2., Marín, N.L.

Pinheiro, A.C., Bourbon, A.I., Cerqueira, M.A., Maricato, É., Nunes, C., Coimbra, M.A. Vicente, A.A., 2015. Chitosan/fucoidan multilayer nanocapsules as a vehicle for controlled release of bioactive compounds. Carbohydr. Polym. 115, 1-9, http:// dx.doi.org/10.1016/j.carbpol.2014.07.016.

Raybaudi-Massilia, R.M., Mosqueda-Melgar, J., Martín-Belloso, O., 2008. Edible alginate-based coating as carrier of antimicrobials to improve shelf-life and safety of fresh-cut melon. Int. J. Food Microbiol. 121, 313-327, http://dx.doi. org/10.1016/j.ijfoodmicro.2007.11.010.

Rodríguez, E.R., Darias Martín, J., Díaz Romero, C., 2010. Aloe vera as a functional ingredient in foods. Crit. Rev. Food Sci. Nutr. 50, 305-326, http://dx.doi.org/10. 1080/10408390802544454.

Rodríguez-García, R., Jasso De Rodríguez, D., Gil-Marín, J.A., Angulo-Sánchez, J.L. Lira-Saldivar, R.H., 2007. Growth, stomatal resistance, and transpiration of Aloe vera under different soil water potentials. Ind. Crops Prod. 25, 123-128, http:// dx.doi.org/10.1016/j.indcrop.2006.08.005.

Rodríguez-González, V.M., Femenia, A., González-Laredo, R.F., Rocha-Guzmán, N.E. Gallegos-Infante, J.A., Candelas-Cadillo, M.G., Ramírez-Baca, P., Simal, S., Rosselló, C., 2011. Effects of pasteurization on bioactive polysaccharide acemannan and cell wall polymers from Aloe barbadensis Miller. Carbohydr. Polym. 86, 1675-1683, http://dx.doi.org/10.1016/j.carbpol.2011.06.084.

Sogvar, O.B., Koushesh Saba, M., Emamifar, A., 2016. Aloe vera and ascorbic acid coatings maintain postharvest quality and reduce microbial load of strawberry fruit. Postharvest Biol. Technol. 114, 29-35, http://dx.doi.org/10.1016/j. postharvbio.2015.11.019.

Surjushe, A., Vasani, R., Saple, D.G., 2008. Aloe vera: a short review. Indian J. Dermatol. 53, 163-166, http://dx.doi.org/10.4103/0019-5154.44785.

Vega-Gálvez, A., Miranda, M., Aranda, M., Henriquez, K., Vergara, J., Tabilo-Munizaga, G., Pérez-Won, M., 2011a. Effect of high hydrostatic pressure on functional properties and quality characteristics of Aloe vera gel (Aloe barbadensis Miller). Food Chem. 129, 1060-1065, http://dx.doi.org/10.1016/j. foodchem.2011.05.074.

Vega-Gálvez, A., Uribe, E., Perez, M., Tabilo-Munizaga, G., Vergara, J., Garcia-Segovia, P., Lara, E., Di Scala, K., 2011b. Effect of high hydrostatic pressure pretreatment on drying kinetics, antioxidant activity, firmness and microstructure of Aloe vera (Aloe barbadensis Miller) gel. LWT: Food Sci. Technol. 44, 384-391, http://dx.doi.org/10.1016/j.lwt.2010.08.004.

Vieira, J.M., Flores-López, M.L., Jasso de Rodríguez, D., Sousa, M.C., Vicente, A.A. Martins, J.T., 2016. Effect of chitosan-Aloe vera coating on postharvest quality of blueberry (Vaccinium corymbosum) fruit. Postharvest Biol. Technol. 116, 88-97, http://dx.doi.org/10.1016/j.postharvbio.2016.01.011.

Zapata, P.J., Navarro, D., Guillén, F., Castillo, S., Martínez-Romero, D., Valero, D. Serrano, M., 2013. Characterisation of gels from different Aloe spp. as antifungal treatment: potential crops for industrial applications. Ind. Crops Prod. 42, 223-230, http://dx.doi.org/10.1016/j.indcrop.2012.06.002.

Zengin, G., Nithiyanantham, S., Locatelli, M., Ceylan, R., Uysal, S., Aktumsek, A., Selvi, P.K., Maskovic, P., 2015. Screening of in vitro antioxidant and enzyme inhibitory activities of different extracts from two uninvestigated wild plants: Centranthus longiflorus subsp. longiflorus and Cerinthe minor subsp. auriculata. Eur. J. Integr. Med., http://dx.doi.org/10.1016/j.eujim.2015.12.004. 